\title{
Prolonged post-recurrence survival following pleurectomy/decortication for malignant pleural mesothelioma
}

\author{
YUICHIRO KAI, YASUHIRO TSUTANI, NORIFUMI TSUBOKAWA, \\ MASAOKI ITO, TAKESHI MIMURA, YOSHIHIRO MIYATA and MORIHITO OKADA
}

\begin{abstract}
Department of Surgical Oncology, Research Institute for Radiation Biology and Medicine, Hiroshima University, Hiroshima 734-8551, Japan
\end{abstract}

Received August 16, 2018; Accepted December 21, 2018

DOI: $10.3892 /$ ol.2019.9979

\begin{abstract}
The present study analyzed surgical results in patients with malignant pleural mesothelioma (MPM) who underwent extrapleural pneumonectomy (EPP) or pleurectomy/decortication (P/D). Data for 44 patients who achieved macroscopic complete resection following neoadjuvant chemotherapy followed by EPP $(n=29)$ or P/D $(n=15)$ were reviewed. Patient demographics and oncological outcomes were compared between the EPP and P/D groups. The median overall (OS) and progression-free survival (PFS) times were 22 and 14 months, respectively. OS was significantly different between the EPP and P/D groups (median OS, 17 vs. 34 months; 5-year OS, 11 vs. 44\%; $\mathrm{P}=0.019$ ); no difference was noted in PFS (median PFS, 13 vs. 21 months; 5-year PFS, 11 vs. $17 \% ; \mathrm{P}=0.373)$. Univariate analysis demonstrated that epithelial histology $(\mathrm{P}=0.0003)$ and $\mathrm{P} / \mathrm{D}(\mathrm{P}=0.018)$ were significant favorable prognostic factors for OS. Using multivariate analysis, epithelial histology $(\mathrm{P}=0.001)$ remained the only significant factor. Post-recurrence survival (PRS) among all patients was significantly longer in the P/D group (median PRS, 3 vs. 20 months; 1.5 -year PRS, 5 vs. 54\%; $\mathrm{P}=0.003$ ), even among patients with epithelial-type MPM (median PRS, 6 s vs. 20 months; 1.5 -year PRS, 8 vs. $61 \%$; $\mathrm{P}=0.012$ ). Chemotherapy following recurrence $(\mathrm{P}=0.033)$ was significantly associated with superior PRS in multivariate analysis. Postoperative pulmonary function was significantly improved in the $P / D$ group. In summary, P/D may be an alternative procedure to EPP for resectable MPM providing similar PFS and improved PRS.
\end{abstract}

Correspondence to: Professor Morihito Okada, Department of Surgical Oncology, Research Institute for Radiation Biology and Medicine, Hiroshima University, 1-2-3-Kasumi, Minami-ku, Hiroshima City, Hiroshima 734-8551, Japan

E-mail: morihito@hiroshima-u.ac.jp

Key words: mesothelioma, extrapleural pneumonectomy, pleurectomy/decortication, post-recurrence survival, pulmonary function

\section{Introduction}

The prognosis of malignant pleural mesothelioma (MPM) is extremely poor with an increasing incidence rate worldwide $(1,2)$. Multimodal therapies have been adopted for MPM, including surgery, chemotherapy and radiotherapy (3). In particular, the goal of radical surgery is to achieve macroscopic complete resection (MCR) (4) obtained via extrapleural pneumonectomy (EPP) or pleurectomy/decortication (P/D). EPP involves the en bloc resection of the ipsilateral lung and the pleura, diaphragm, and pericardium (5-7). P/D includes the removal of the ipsilateral pleura and preservation of the lung parenchyma (8). Therefore, EPP is a lung-sacrificing surgery, whereas $\mathrm{P} / \mathrm{D}$ is a lung-sparing surgery.

Certain studies identified benefits of $\mathrm{P} / \mathrm{D}$ regarding postoperative survival $(9,10)$. Two previous meta-analyses comparing EPP and P/D revealed no statistical difference in long-term survival, although P/D was associated with lower morbidity and mortality rates $(11,12)$. Due to these results, many centers have shifted their surgical approach for MPM from EPP to $\mathrm{P} / \mathrm{D}$. Comparing EPP and P/D, little is understood regarding recurrence rates, and few studies have focused on survival and treatment implementation rates following recurrence.

Recently, we adopted P/D due to the reports of its comparable survival and decreased morbidity and mortality rates. The purpose of the present study was to investigate surgical results, including post-recurrence survival (PRS), in patients treated with EPP or P/D for MPM.

\section{Patients and methods}

Patients. The current retrospective study included all patients who attained MCR following EPP or P/D for MPM at Hiroshima University (Hiroshima, Japan) between April 2005 and December 2017. All patients were male and the median age of diagnosis was 65 (range, $42-73$ years). The study was approved by the institutional review board of Hiroshima University (Hiroshima, Japan).

Thoracoscopic pleural biopsy was performed to diagnose MPM. A pathological diagnosis was achieved histologically and immunohistochemically. All patients underwent routine blood examination, pulmonary function tests (PFTs) and computed tomography (CT) of the chest, abdomen 
and brain. All patients, excluding one diagnosed in 2005, underwent F-18-fluorodeoxyglucose positron emission tomography (FDG-PET)/CT. Clinical operability was evaluated by performance status (PS), pulmonary function and clinical staging, which was determined according to the Tumor-Node-Metastasis staging system (8th Edition) proposed by the International Mesothelioma Interest Group (13).

Patients with clinically resectable MPM were selected (T1-3 N0-2 M0, PS 0-1, age < 75 years). All patients received neoadjuvant chemotherapy. Three or four cycles of cisplatin-based chemotherapy were completed. All but 1 patient received pemetrexed as the second agent. In addition, 1 patient received gemcitabine in 2005 .

Surgical procedures and pathological staging. EPP was performed via the standard technique (14). P/D involved the total removal of the parietal, viscera and mediastinal pleura, and preservation of the lung parenchyma. Until July 2011, the primary intervention was EPP. After August 2011, the primary intervention was P/D. The conversion of P/D to EPP was based on patients' condition, including lung function and intraoperative findings, including the degree of tumor invasion. In both procedures, the pericardium and diaphragm were reconstructed if required, and mediastinal lymph node dissection was performed. Surgical complications were classified according to the Clavien-Dindo classification (15). Pathological staging was performed according to the evaluation of the surgical specimen and intraoperative findings. The histopathological effect (EF) of treatment was classified according to 'General Rule for Clinical and Pathological Record of Lung Cancer' (8th Edition) in Japan (16) as follows: Ef. 0, no pathological response; Ef. 1, slight pathological response; Ef. 2, moderate pathological response; and Ef. 3, complete pathological response.

Postoperative follow-up. Postoperatively, adjuvant wholehemi-thorax radiotherapy was offered to patients who underwent EPP and adjuvant single-agent chemotherapy to those who underwent $\mathrm{P} / \mathrm{D}$ following consideration of their choice and performance status. All patients were followed up at least every 3 months for 1 year and then every 6 months until mortality or the last follow-up. Patients underwent physical and clinical examinations, and CT. Additional evaluations, including FDG-PET/CT, were performed on the basis of the judgment of the attending physician.

Tumor recurrence was classified into three main groups: i) locoregional, ii) distant, and iii) both. Locoregional recurrence occurred in the ipsilateral hemi-thorax. Distant recurrence occurred at the contralateral hemi-thorax and other distant sites. Patients with good performance status following recurrence received chemotherapy.

zStatistical analysis. Categorical variables and continuous variables were analyzed using the $\chi^{2}$ or Fisher's exact test and Student's t-test or Mann-Whitney's U-test, respectively. Overall survival (OS) was calculated from the date of pleural biopsy until that of mortality or the last follow-up. Progression-free survival (PFS) was calculated from the date of pleural biopsy until that of recurrence, mortality or the last follow-up. Post-recurrence survival (PRS) was calculated from the date of recurrence until that of mortality or the last follow-up. The
Kaplan-Meier method was used to estimate OS, PFS and PRS. Survival differences were compared using the log-rank test. Multivariate analysis of prognostic factors was performed using Cox's proportional hazards regression model. All statistical analysis was performed using SPSS 20.0 software (IBM Corp., Armonk, NY, USA). P $<0.05$ was considered to indicate a statistically significant difference.

\section{Results}

A total of 50 patients underwent a surgical intervention for MPM following neoadjuvant chemotherapy. From April 2005 to July 2011, 25 patients underwent EPP. Among them, 20 patients attained MCR via EPP and 5 patients required an exploratory thoracotomy. From August 2011 to December 2017, 25 patients underwent P/D. Among them, 15 patients attained MCR via P/D and 9 patients shifted to EPP to achieve MCR. Only 1 patient required exploratory thoracotomy. MCR was achieved in 44 patients (29 EPP and 15 P/D; Fig. 1), 18 patients $(62 \%)$ in the EPP group received adjuvant radiotherapy and 8 patients (53\%) in the P/D received adjuvant chemotherapy.

Patient demographics, including pre-/intra-/postoperative data, are presented in Tables I-II. All patients, except one, received pemetrexed and cisplatin as neoadjuvant chemotherapy. The median operative time was significantly longer for $\mathrm{P} / \mathrm{D}$ compared with EPP $(\mathrm{P}<0.0001)$. In the $\mathrm{P} / \mathrm{D}$ group, the histology of all patients except one was the epithelial type. The 90-day mortality rate was $6.9 \%$ for the EPP group and $0 \%$ for the $\mathrm{P} / \mathrm{D}(\mathrm{P}=0.429)$.

The median follow-up period was 48 months (54 months in the EPP group and 43 months in the P/D group). The median and 5-year OS time of all patients was 22 months [95\% confidence interval $(\mathrm{CI})=14.2-27.8]$ and $20 \%$, respectively (Fig. 2A). The median and 5-year PFS time of all patients was 14 months (95\% CI, 11.9-16.1) and 13\%, respectively (Fig. 2B). OS was significantly different between the EPP and P/D groups for all patients (median OS time, 17 vs. 34 months; 5-year OS, 11 vs. 44\%; $\mathrm{P}=0.019$; Fig. 2C), whereas no difference was observed for PFS (median PFS time, 13 vs. 21 months; 5-year PFS, 11 vs. 17\%; P=0.373; Fig. 2D). In patients with epithelial histology, no significant difference was identified in OS (median OS time, 28 vs. 34 months; 5-year OS, 20 vs. 47\%; P=0.162; Fig. 2E) or PFS (median PFS time, 21 vs. 21 months; 5-year PFS, 20 vs. 18\%; P=0.910; Fig. 2F) between the two groups. Univariate analysis, including age, final histology, pathological stage, histopathological effect and surgical procedure, identified epithelial histology [hazard ratio (HR), 0.203; 95\% CI, 0.085-0.471; $\mathrm{P}=0.0003]$ and $\mathrm{P} / \mathrm{D}$ $(\mathrm{HR}=0.388 ; 95 \% \mathrm{CI}, 0.154-0.855 ; \mathrm{P}=0.018)$ as significant favorable prognostic factors of OS (Table III). Following multivariate analysis, only epithelial histology (HR, 0.224; 95\% CI, 0.086-0.557; $\mathrm{P}=0.001$ ) remained a significant prognostic factor for OS (Table III).

The recurrence rates following EPP and P/D were 76\% (22/29 patients) and 67\% (10/15 patients), respectively (Table IV). No significant difference was revealed for the type of tumor recurrence, including locoregional, distant and both, between the groups $(\mathrm{P}=0.705)$. Among the 32 patients who developed recurrence, 17 patients $(53 \%)$ received chemotherapy, including 9 patients (41\%) in the EPP group and 
Table I. Preoperative patient demographics.

\begin{tabular}{|c|c|c|c|c|}
\hline Variables & Total $(n=44)$ & $\operatorname{EPP}(n=29)$ & $\mathrm{P} / \mathrm{D}(\mathrm{n}=15)$ & P-value \\
\hline Median age, years (range) & $65(42-73)$ & $64(42-73)$ & $66(48-72)$ & 0.278 \\
\hline \multicolumn{5}{|l|}{ Sex, n (\%) } \\
\hline Male & $44(100)$ & $29(100)$ & $15(100)$ & \\
\hline \multicolumn{5}{|l|}{ Side, n (\%) } \\
\hline Right & $25(57)$ & $16(55)$ & $9(60)$ & \multirow[t]{2}{*}{0.759} \\
\hline Left & $19(43)$ & $13(45)$ & $6(40)$ & \\
\hline \multicolumn{5}{|l|}{ IMIG cStage, n (\%) } \\
\hline I & $11(25)$ & $8(28)$ & $3(20)$ & \multirow[t]{3}{*}{0.364} \\
\hline II & $14(32)$ & $7(24)$ & $7(47)$ & \\
\hline III & $19(43)$ & $14(48)$ & $5(33)$ & \\
\hline \multicolumn{5}{|l|}{ Pleural biopsy, n (\%) } \\
\hline Epithelioid & $36(82)$ & $21(72)$ & $15(100)$ & \multirow[t]{3}{*}{0.076} \\
\hline Biphasic & $6(14)$ & $6(21)$ & $0(0)$ & \\
\hline Sarcomatoid & $2(4)$ & $2(7)$ & $0(0)$ & \\
\hline \multicolumn{5}{|c|}{ Induction chemotherapy, n (\%) } \\
\hline $\mathrm{CDDP}+\mathrm{PEM}$ & $43(98)$ & $28(97)$ & $15(100)$ & \multirow[t]{2}{*}{0.659} \\
\hline CDDP+GEM & $1(2)$ & $1(3)$ & $0(0)$ & \\
\hline \multicolumn{5}{|l|}{ Modified RECIST, n (\%) } \\
\hline CR & $2(5)$ & $1(4)$ & $1(7)$ & \multirow[t]{4}{*}{0.383} \\
\hline PR & $20(45)$ & $11(37)$ & $9(60)$ & \\
\hline SD & $21(48)$ & $16(55)$ & $5(33)$ & \\
\hline PD & $1(2)$ & $1(4)$ & $0(0)$ & \\
\hline
\end{tabular}

CDDP, cisplatin; CR, complete response; EPP, extrapleural pneumonectomy; GEM, gemcitabine; IMIG, International Mesothelioma Interest Group; PD, progressive disease; P/D, pleurectomy/decortication; PEM, pemetrexed; PR, partial response; RECIST, response evaluation criteria in solid tumors; $\mathrm{SD}$, stable disease.

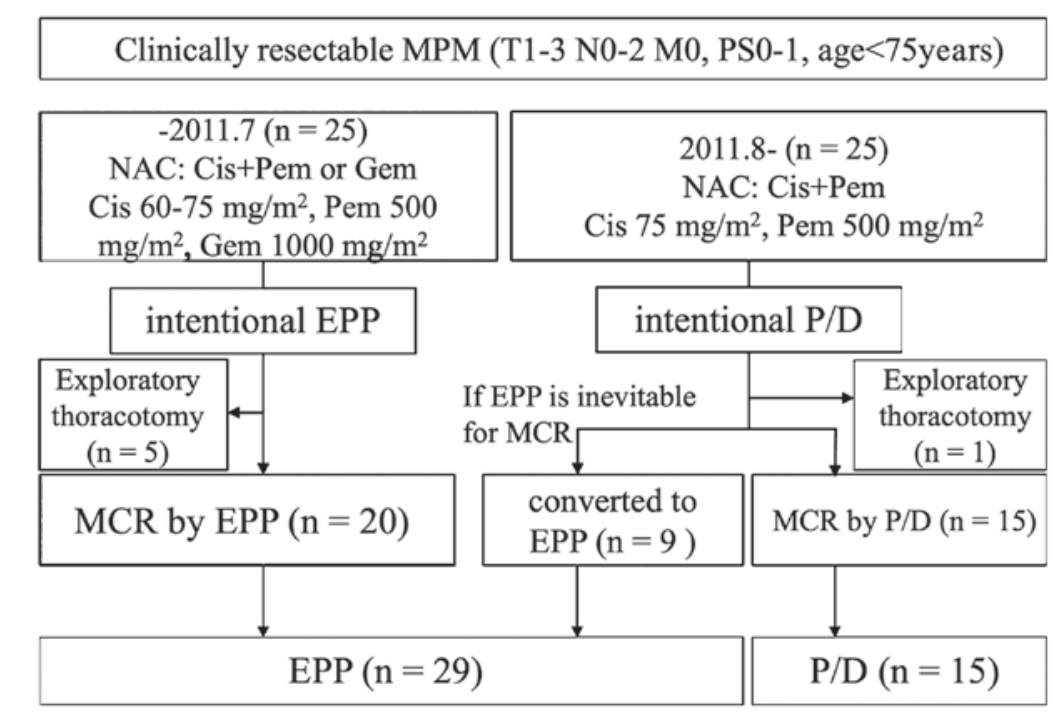

Figure 1. Surgical strategy for resectable MPM. Intentional EPP was conducted prior to July 2011 and intentional P/D was conducted after August 2011. Cis, cisplatin; EPP, extrapleural pneumonectomy; Gem, gemcitabine; MCR, macroscopic complete resection; MPM, malignant pleural mesothelioma; NAC, neoadjuvant chemotherapy; P/D, pleurectomy/decortication; Pem, pemetrexed.

8 patients $(80 \%)$ in the $\mathrm{P} / \mathrm{D}$ (Table IV). Patients in the P/D group demonstrated a higher likelihood of receiving chemotherapy following recurrence $(\mathrm{P}=0.046)$.
The median PRS time was 5 months (95\% CI, 1.755-8.245). PRS was significantly longer in the P/D group compared with the EPP group (median PRS time, 3 vs. 20 months; 1.5-year 
Table II. Intra/postoperative patient demographics.

\begin{tabular}{|c|c|c|c|c|}
\hline Variables & Total $(n=44)$ & $\operatorname{EPP}(n=29)$ & $\mathrm{P} / \mathrm{D}(\mathrm{n}=15)$ & P-value \\
\hline Median operation time, min (range) & $532(321-733)$ & $515(321-647)$ & $586(488-733)$ & $<0.0001$ \\
\hline Median surgical bleeding, ml (range) & $2,230(520-7,973)$ & $2,130(520-4,360)$ & $2,610(1,230-7,973)$ & 0.083 \\
\hline Median drainage time, day (range) & $5(2-99)$ & $5(2-99)$ & $6(4-55)$ & 0.093 \\
\hline Median postoperative hospital stay, day (range) & $26(14-196)$ & $26(16-196)$ & $29(14-151)$ & 0.696 \\
\hline \multicolumn{5}{|l|}{ Grade of complication (Clavien-Dindo classification) ${ }^{\mathrm{a}}$} \\
\hline Grade $\geq \mathrm{IIIb}$ & $10(23)$ & $6(21)$ & $4(27)$ & \multirow{2}{*}{0.464} \\
\hline Grade $<$ IIIa & $34(77)$ & $23(79)$ & $11(73)$ & \\
\hline 90-day mortality rate, $\mathrm{n}(\%)$ & $2(5)$ & $2(7)$ & $0(0)$ & 0.429 \\
\hline \multicolumn{5}{|l|}{ Final histology, n (\%) } \\
\hline Epithelioid & $31(70)$ & $17(58)$ & $14(93)$ & \multirow[t]{3}{*}{0.053} \\
\hline Biphasic & $11(25)$ & $10(35)$ & $1(7)$ & \\
\hline Sarcomatoid & $2(5)$ & $2(7)$ & $0(0)$ & \\
\hline \multicolumn{5}{|l|}{ Histopathological effect (EF), n (\%) } \\
\hline Ef. 0 & $8(18)$ & $7(24)$ & $1(7)$ & \multirow[t]{4}{*}{0.239} \\
\hline Ef. 1 & $30(68)$ & $17(59)$ & $13(86)$ & \\
\hline Ef. 2 & $6(14)$ & $5(17)$ & $1(7)$ & \\
\hline Ef. 3 & $0(0)$ & $0(0)$ & $0(0)$ & \\
\hline \multicolumn{5}{|l|}{ IMIG pStage, n (\%) } \\
\hline $\mathrm{I}$ & $6(14)$ & $3(10)$ & $3(20)$ & \multirow[t]{4}{*}{0.597} \\
\hline II & $16(36)$ & $10(35)$ & $6(40)$ & \\
\hline III & $15(34)$ & $10(35)$ & $5(33)$ & \\
\hline IV & $7(16)$ & $6(20)$ & $1(7)$ & \\
\hline
\end{tabular}

EPP, extrapleural pneumonectomy; IMIG, International Mesothelioma Interest Group; P/D, pleurectomy/decortication. ${ }^{\mathrm{a}}(15)$.

Table III. Univariate and multivariate Cox regression analysis of overall survival with malignant pleural mesothelioma.

\begin{tabular}{|c|c|c|c|c|c|c|}
\hline \multirow[b]{2}{*}{ Variables } & \multicolumn{3}{|c|}{ Univariate } & \multicolumn{3}{|c|}{ Multivariate } \\
\hline & Hazard ratio & $95 \% \mathrm{CI}$ & P-value & Hazard ratio & $95 \% \mathrm{CI}$ & P-value \\
\hline Age, $<64$ (vs. $\geq 64$ ) years & 0.961 & $0.477-1.911$ & 0.91 & 1.177 & $0.555-2.499$ & 0.669 \\
\hline Final histology, Epi (vs. non-Epi) & 0.203 & $0.085-0.471$ & 0.0003 & 0.224 & $0.086-0.557$ & 0.001 \\
\hline IMIG pStage, I+II (vs. III+IV) & 0.689 & $0.337-1.394$ & 0.299 & 0.691 & $0.324-1.457$ & 0.33 \\
\hline Histopathological effect, grade 2 (vs. 0/1) & 1.034 & $0.384-2.358$ & 0.941 & 0.896 & $0.312-2.283$ & 0.825 \\
\hline Procedure, P/D (vs. EPP) & 0.388 & $0.154-0.855$ & 0.018 & 0.568 & $0.212-1.379$ & 0.217 \\
\hline
\end{tabular}

CI, confidence interval; Epi, epithelioid; EPP, extrapleural pneumonectomy; P/D, pleurectomy/decortication; IMIG, International Mesothelioma Interest Group.

PRS, 5 vs. 54\%; $\mathrm{P}=0.003$; Fig. 3A), even among patients with epithelial-type disease (median PRS time, 6 vs. 20 months; 1.5 -year PRS, 8 vs. $61 \%$; $\mathrm{P}=0.012$; Fig. 3B). Patients who received chemotherapy following recurrence presented with a significantly longer PRS compared with those who did not receive chemotherapy (median PRS time, 15 vs. 1 months; 1.5-year PRS time, 36 vs. 0\%; P=0.0001; Fig. 3C). The same was true for patients with epithelial-type disease (median PRS time, 18 vs. 2 months; 1.5 -year PRS, 49 vs. $0 \%$; $\mathrm{P}=0.001$; Fig. 3D). Univariate analysis, including age, final histology, pathological stage, chemotherapy following recurrence, histopathological effect and surgical procedure, indicated that epithelial histology (HR, 0.255; 95\% CI, 0.100-0.631; $\mathrm{P}=0.004)$, chemotherapy following recurrence $(\mathrm{HR}, 0.225$; 95\% CI, 0.092-0.52; $\mathrm{P}=0.0005$ ), and P/D (HR, 0.238; 95\% CI, 0.076-.618; $\mathrm{P}=0.002)$ were significant favorable prognostic factors for PRS (Table V). With multivariate analysis, chemotherapy following recurrence (HR, 0.318; 95\% CI, $0.101-0.911 ; \mathrm{P}=0.033)$ was the only significant prognostic factor for PRS (Table V).

In total, 22 patients were assessed for VC and FEV1 (12 EPP and 10 P/D) and 16 patients were assessed for DLCO 
Table IV. Patients with recurrent malignant pleural mesothelioma.

\begin{tabular}{lccc}
\hline Variables & Total $(\mathrm{n}=32)$ & EPP $(\mathrm{n}=22)$ & P/D (n=10) \\
\hline Sites of recurrence, $\mathrm{n}(\%)$ & & & $2(20)$ \\
$\quad$ Locoregional & $8(25)$ & $6(27)$ & $3(30)$ \\
Distant & $12(37.5)$ & $9(41)$ & $5(50)$ \\
Both & $12(37.5)$ & $7(32)$ & $2(20)$ \\
Chemotherapy following recurrence, $\mathrm{n}(\%)$ & $15(47)$ & $13(59)$ & $8(80)$
\end{tabular}

EPP, extrapleural pneumonectomy; P/D, pleurectomy/decortication.

Table V. Univariate and multivariate Cox regression analysis of post recurrence survival with malignant pleural mesothelioma.

\begin{tabular}{|c|c|c|c|c|c|c|}
\hline \multirow[b]{2}{*}{ Variables } & \multicolumn{3}{|c|}{ Univariate } & \multicolumn{3}{|c|}{ Multivariate } \\
\hline & Hazard ratio & $95 \% \mathrm{CI}$ & P-value & Hazard ratio & $95 \% \mathrm{CI}$ & P-value \\
\hline Age, $<64$ (vs. $\geq 64$ ) years & 0.984 & $0.455-2.112$ & 0.966 & 1.144 & $0.51-2.573$ & 0.742 \\
\hline Final histology, Epi (vs. non-Epi) & 0.255 & $0.1-0.631$ & 0.004 & 0.402 & $0.147-1.057$ & 0.065 \\
\hline IMIG pStage, I+II (vs. III+IV) & 0.563 & $0.25-1.222$ & 0.147 & 1.000 & $0.354-2.873$ & 1.000 \\
\hline $\begin{array}{l}\text { Chemotherapy following recurrence } \\
\text { (vs. no chemotherapy) }\end{array}$ & 0.225 & $0.092-0.52$ & 0.0005 & 0.318 & $0.101-0.911$ & 0.033 \\
\hline Histopathological effect, grade 2 (vs. 0/1) & 0.863 & $0.286-2.146$ & 0.766 & 0.54 & $0.151-1.661$ & 0.291 \\
\hline Procedure, P/D (vs. EPP) & 0.238 & $0.076-0.618$ & 0.002 & 0.397 & $0.112-1.219$ & 0.109 \\
\hline
\end{tabular}

CI, confidence interval; Epi, epithelioid; EPP, extrapleural pneumonectomy; P/D, pleurectomy/decortication; IMIG, International Mesothelioma Interest Group.
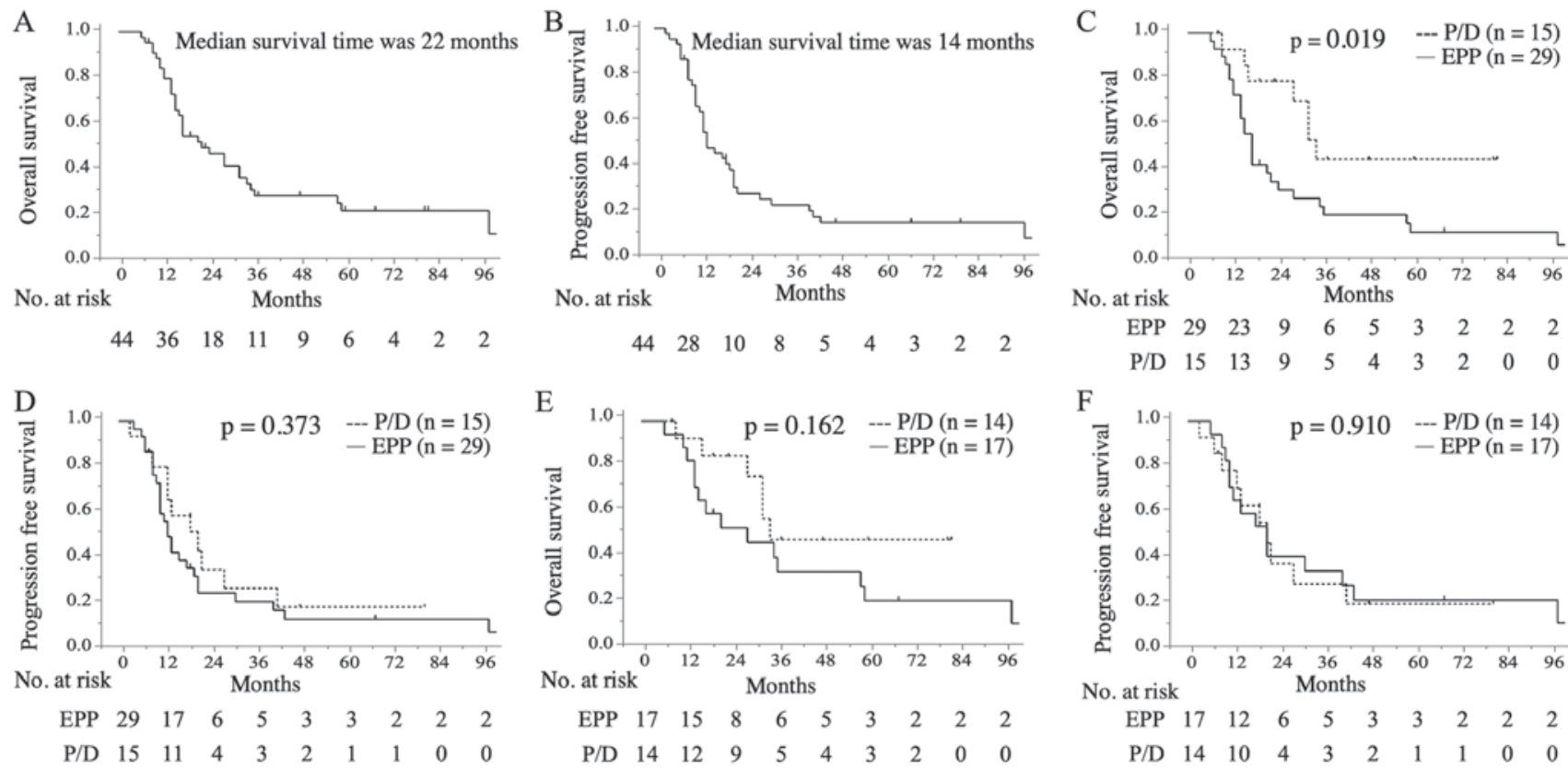

Figure 2. Kaplan-Meier analysis of OS and PFS. (A) OS time for all patients. The median survival time was 22 months (95\% CI, 14.2-27.8). (B) PFS time for all patients. The median survival time was 14 months (95\% CI, 11.9-16.1). (C) OS rates in the EPP $(\mathrm{n}=29)$ and P/D groups $(\mathrm{n}=15)$. The 5-year survival rates were 11 and 44\%, respectively ( $\mathrm{P}=0.019)$. (D) PFS rates in the EPP and P/D groups. The 5-year survival rates were 11 and $17 \%$, respectively (P=0.373). (E) OS rates in the EPP $(n=17)$ and $P / D$ groups $(n=14)$ among patients with epithelial-type disease. The 5 -year survival rates were 20 and $47 \%$, respectively $(P=0.162)$. (F) PFS rates in the EPP and P/D groups among patients with epithelial-type disease. The 5-year survival rates were 20 and $18 \%$, respectively ( $\mathrm{P}=0.910$ ). $\mathrm{CI}$, confidence interval; EPP, extrapleural pneumonectomy; OS, overall survival; P/D, pleurectomy/decortication; PFS, progression-free survival. 

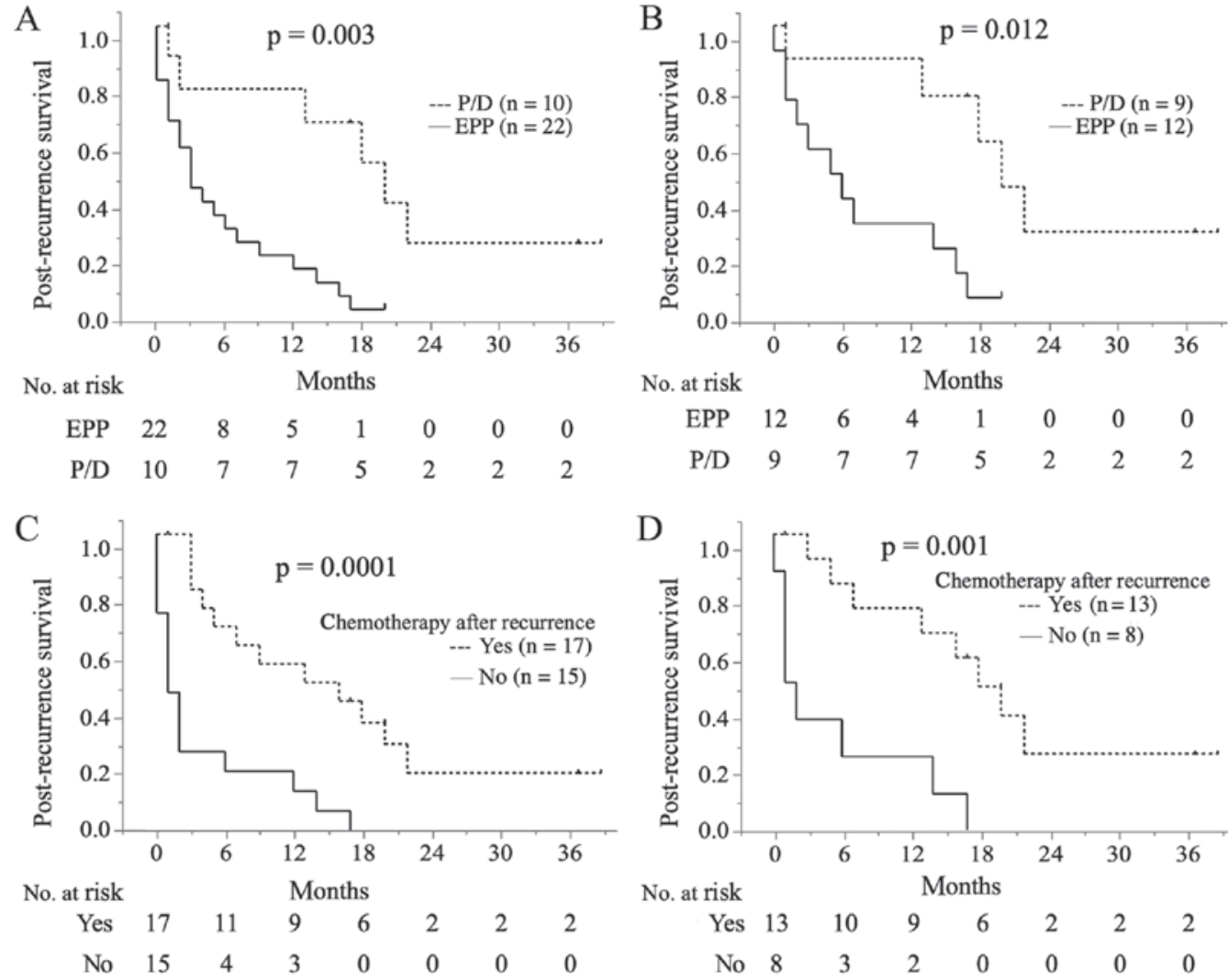

Figure 3. Kaplan-Meier analysis of PRS. (A) EPP ( $n=22)$ vs. $P / D(n=10)$ for all patients $(P=0.003)$. (B) EPP ( $n=12)$ vs. P/D ( $n=9)$ for patients with epithelial-type disease $(\mathrm{P}=0.012)$. (C) Chemotherapy $(\mathrm{n}=17)$ vs. no chemotherapy $(\mathrm{n}=15)$ for all patients $(\mathrm{P}=0.0001)$. (D) Chemotherapy $(\mathrm{n}=13)$ vs. no chemotherapy $(\mathrm{n}=8)$ for patients with epithelial-type disease $(\mathrm{P}=0.001)$. EPP, extrapleural pneumonectomy; $\mathrm{P} / \mathrm{D}$, pleurectomy/decortication; PRS, post-recurrence survival.
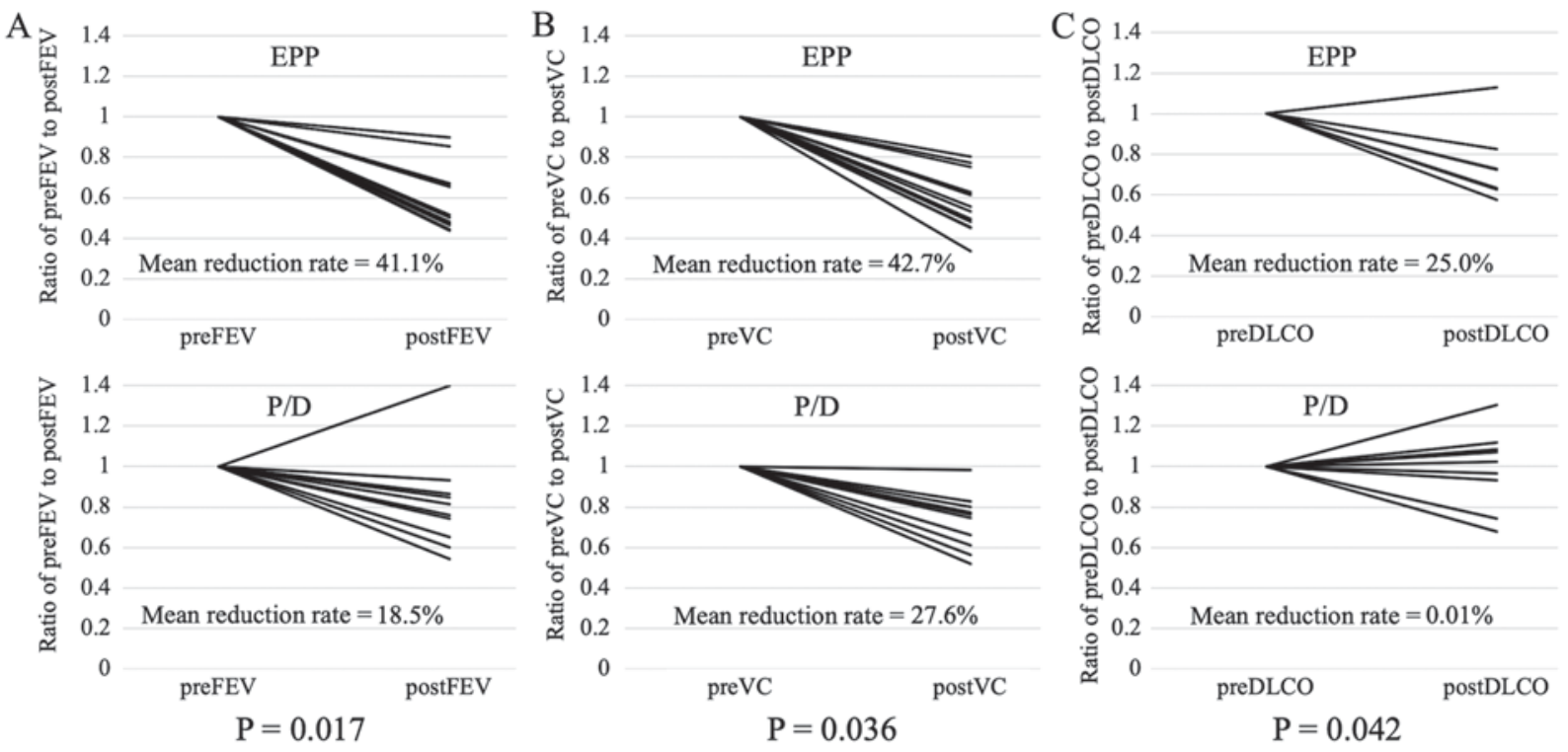

Figure 4. Reduction rates of postoperative pulmonary function. (A) Rate-of-change analysis of FEV1 following EPP vs. P/D. (B) Rate-of-change analysis of VC following EPP vs. P/D. (C) Rate-of-change analysis of DLCO following EPP vs. P/D. DLCO, diffusing capacity of the lung carbon monoxide; EPP, extrapleural pneumonectomy; FEV1, forced expiratory volume in $1 \mathrm{sec}$; P/D, pleurectomy/decortication; VC, vital capacity.

(7 EPP and 9 P/D). FEV1 (average reduction rate, 41 vs. 19\%; $\mathrm{P}=0.017$ ), $\mathrm{VC}$ (average reduction rate, 43 vs. $28 \% ; \mathrm{P}=0.036$ ) and DLCO (average reduction rate, 25 vs. $0.01 \% ; \mathrm{P}=0.042$ ) following surgery were significantly improved in the P/D group compared with the EPP group (Fig. 4)

\section{Discussion}

The present retrospective study compared surgical outcomes between EPP and P/D. A number of studies have demonstrated that patients with epithelial histology have a significantly 
longer survival time compared with those with non-epithelial histology (17-19); the current multivariate analysis of OS time revealed the same result. When the study subjects were limited to those with epithelial MPM, no significant difference was identified in OS or PFS time between the two groups. However, PRS was significantly improved in patients who underwent $\mathrm{P} / \mathrm{D}$ compared with those who underwent EPP. In addition, patients who received chemotherapy following recurrence had a significantly longer PRS time. The majority of patients undergoing P/D could receive chemotherapy.

Several studies have demonstrated that patients who undergo P/D have improved survival compared with those who undergo EPP $(9,10,20)$; however, other studies have reported no difference in survival (21-23). The optimal surgical procedure with resectable MPM remains to be established due to the lack of randomized prospective studies comparing the surgical procedures; however, the majority of studies including the present study have demonstrated that prognosis is comparable between EPP and P/D, which suggests that P/D can be an alternative procedure to EPP.

Locoregional recurrence remains the main problem for MPM and various treatments have been employed, including adjuvant chemotherapy or radiotherapy $(24,25)$. A number of studies have reported that EPP can provide improved local control, i.e free from recurrence in the ipsilateral hemithorax. $\mathrm{P} / \mathrm{D}$ has a major disadvantage of high local recurrence rates $(26,27)$. However, in the current analysis, the PFS curve between the two groups was similar, suggesting that P/D can also adequately provides local control for MPM. It is essential for EPP or P/D to conduct trimodality therapy and remove as much visible tumor as possible. Even when EPP is performed, positive microscopic margins are almost inevitable $(17,28)$. Recently, two retrospective studies reported that disease-free survival rates were similar between EPP and P/D (29,30). Similar to the present study, these studies also adopted cisplatin/pemetrexed as induction chemotherapy and resected the diaphragm and/or pericardium if required for MCR. Precise surgery for obtaining MCR including trimodality therapy as well as selection of surgical procedures appeared to serve a critical role in acquiring the local control.

Although PFS was similar between the two groups, OS was improved for P/D compared with EPP, which suggests that surgical results could differ following recurrence. Therefore, the current study also assessed PRS and treatments following recurrence, which demonstrated that patients undergoing P/D exhibited a significantly improved PRS compared with those undergoing EPP regardless of the histologic type. In addition, the majority of patients who underwent $\mathrm{P} / \mathrm{D}$ received chemotherapy following recurrence, unlike the majority of those who underwent EPP. A recent retrospective study reported that second-line treatment following EPP can prolong PRS (31). In the present study, chemotherapy following recurrence improved PRS for patients with MPM regardless of the surgical procedure. To the best of our knowledge, this is the first report to demonstrate that $\mathrm{P} / \mathrm{D}$ prolongs survival rates following recurrence in patients with MPM.

The current results raise the question of why $\mathrm{P} / \mathrm{D}$ can improve PRS. P/D is a less invasive surgical procedure compared with EPP. In the present study, the 90-day mortality rate following
$\mathrm{P} / \mathrm{D}$ was $0 \%$, compared with a mortality rate of $6.9 \%$ for EPP, although this difference was not statistically significant. By preserving the ipsilateral lung, the postoperative pulmonary function of patients following $\mathrm{P} / \mathrm{D}$ can be preserved to some extent $(32,33)$. This advantage of $\mathrm{P} / \mathrm{D}$ appeared to have a favorable effect on PRS in the present study. The current analysis indicated that pulmonary function following P/D was significantly improved compared with that following EPP. Therefore, chemotherapy was more conducive for patients in the P/D group compared with those in the EPP group following recurrence. Due to the high implementation rates of chemotherapy following recurrence, improvements in PRS may be achieved.

The current study had certain limitations. Firstly, the present study had possible patient selection bias. By chance, after August 2011, all but one tumor had epithelial histology and a significant difference was revealed in the histologic types between the two groups. Therefore, the current study also assessed surgical results in patients according to epithelial-type. In addition, 36\% patients intended for P/D were converted to EPP during the surgery to attain MCR, which may have led to possible selection bias. Furthermore, the present study was a single-center trial with a small sample size. Further research will be necessary to confirm the current findings.

In conclusion, the present study evaluated the survival efficacy of P/D for MPM. P/D provided a similar PFS and improved PRS by preserving postoperative pulmonary function compared with EPP, leading to improved OS. Therefore, $\mathrm{P} / \mathrm{D}$ may be an alternative procedure to EPP for patients with resectable MPM if MCR is achieved.

\section{Acknowledgements}

Not applicable.

\section{Funding}

No funding was received.

\section{Availability of data and materials}

The datasets used and/or analyzed during the present study are available from the corresponding author on reasonable request.

\section{Authors' contributions}

YK, YT, NT, MI, and TM performed statistical interpretation of the data and prepared figures and the manuscript. All the authors reviewed the manuscript. YK, YM and MO were responsible for study design.

\section{Ethics approval and consent to participate}

The present study was approved by the institutional review board of Hiroshima University. The requirement of obtaining informed consent from individual patients was waived because this study was a retrospective review of a patient database.

\section{Patient consent for publication}

Not applicable. 


\section{Competing interests}

The authors declare that they have no competing interests.

\section{References}

1. Robinson BM: Malignant pleural mesothelioma: An epidemiological perspective. Ann Cardiothorac Surg 1: 491-496, 2012.

2. Campbell K, Brosseau S, Reviron-Rabec L, Bergot E, Lechapt E, Levallet G and Zalcman G: Malignant pleural mesothelioma: 2013 state of the art. Bull Cancer 100: 1283-1293, 2013.

3. Federico R, Adolfo F, Giuseppe M, Lorenzo S, Martino DT, Anna C, Adriano P, Gino C, Francesca R and Matteo C: Phase II trial of neoadjuvant pemetrexed plus cisplatin followed by surgery and radiation in the treatment of pleural mesothelioma. BMC Cancer 13: 22, 2013.

4. Rusch V,BaldiniEH,Bueno R, DePerrot M,Flores R, Hasegawa S, Klepetko W, Krug L, Lang-Lazdunski L, Pass H, et al: The role of surgical cytoreduction in the treatment of malignant pleural mesothelioma: Meeting summary of the international mesothelioma interest group congress, September 11-14, 2012, Boston, Mass. J Thorac Cardiovasc Surg 145: 909-910, 2013.

5. Wolf AS, Daniel J and Sugarbaker DJ: Surgical techniques for multimodality treatment of malignant pleural mesothelioma: Extrapleural pneumonectomy and pleurectomy/decortication. Semin Thorac Cardiovasc Surg 21: 132-148, 2009.

6. Yan TD, Boyer M, Tin MM, Wong D, Kennedy C, McLean J, Bannon PG and McCaughan BC: Extrapleural pneumonectomy for malignant pleural mesothelioma: Outcomes of treatment and prognostic factors. J Thorac Cardiovasc Surg 138: 619-624, 2009.

7. Sugarbaker DJ, Jaklitsch MT, Bueno R, Richards W, Lukanich J, Mentzer SJ, Colson Y, Linden P, Chang M, Capalbo L, et al: Prevention, early detection, and management of complications after 328 consecutive extrapleural pneumonectomies. J Thorac Cardiovasc Surg 128: 138-146, 2004.

8. Sugarbaker DJ and Wolf AS: Surgery for malignant pleural mesothelioma. Expert Rev Respir Med 4: 363-372, 2010.

9. Flores RM, Pass HI, Seshan VE, Dycoco J, Zakowski M, Carbone M, Bains MS and Rusch VW: Extrapleural pneumonectomy versus pleurectomy/decortication in the surgical management of malignant pleural mesothelioma: Results in 663 patients. J Thorac Cardiovasc Surg 135: 620-626, 2008.

10. Friedberg JS, Mick R, Culligan M, Stevenson J, Fernandes A, Smith D, Glatstein E, Hahn SM and Cengel K: Photodynamic therapy and the evolution of a lung-sparing surgical treatment for mesothelioma. Ann Thorac Surg 91: 1738-1745, 2011.

11. Cao C, Tian D, Park J, Allan J, Pataky KA and Yan TD: A systematic review and meta-analysis of surgical treatments for malignant pleural mesothelioma. Lung Cancer 83: 240-245, 2014.

12. Taioli E, Wolf AS and Flores RM: Meta-analysis of survival after pleurectomy decortication versus extrapleural pneumonectomy in mesothelioma. Ann Thorac Surg 99: 472-480, 2015.

13. Rusch VW: A proposed new international TNM staging system for malignant pleural mesothelioma. From the international mesothelioma interest group. Chest 108: 1122-1128, 1995.

14. Rice D, Rusch V, Pass H, Asamura H, Nakano T, Edwards J, Giroux DJ, Hasegawa S, Kernstine KH, Waller D, et al: Recommendations for uniform definitions of surgical techniques for malignant pleural mesothelioma: A consensus report of the international association for the study of lung cancer international staging committee and the international mesothelioma interest group. J Thorac Oncol 6: 1304-1312, 2011.

15. Clavien PA, Barkun J, de Oliveira ML, Vauthey JN, Dindo D, Schulick RD, de Santibañes E, Pekolj J, Slankamenac K, Bassi C, et al: The Clavien-Dindo classification of surgical complications: Five-year experience. Ann Surg 250: 187-196, 2009.

16. Society TJLC: General rule for clinical and pathological record of lung cancer. 8th ed. Kanehara, Tokyo, 2017 (In Japanese).

17. Sugarbaker DJ, Flores RM, Jaklitsch MT, Richards WG, Strauss GM, Corson JM, DeCamp MM Jr, Swanson SJ, Bueno R, Lukanich JM, et al: Resection margins, extrapleural nodal status, and cell type determine postoperative long-term survival in trimodality therapy of malignant pleural mesothelioma: Results in 183 patients. J Thorac Cardiovasc Surg 117: 54-63, 1999.
18. Yan TD, Boyer M, Tin MM, Sim J, Kennedy C, McLean J, Bannon PG, McCaughan BC, et al: Prognostic features of long-term survivors after surgical management of malignant pleural mesothelioma. Ann Thorac Surg 87: 1552-1556, 2009.

19. Tsutani Y, Takuwa T, Miyata Y, Fukuoka K, Hasegawa S, Nakano T and Okada M: Prognostic significance of metabolic response by positron emission tomography after neoadjuvant chemotherapy for resectable malignant pleural mesothelioma. Ann Oncol 24: 1005-1010, 2013.

20. Lang-Lazdunski L, Bille A, Lal R, Cane P, McLean E, Landau D, Steele J and Spicer J: Pleurectomy/decortication is superior to extrapleural pneumonectomy in the multimodality management of patients with malignant pleural mesothelioma. J Thorac Oncol 7: 737-743, 2012.

21. Burt BM, Cameron RB, Mollberg NM, Kosinski AS, Schipper PH, Shrager JB and Vigneswaran WT: Malignant pleural mesothelioma and the society of thoracic surgeons database: An analysis of surgical morbidity and mortality. J Thorac Cardiovasc Surg 148: 30-35, 2014.

22. Nakas A, von Meyenfeldt E, Lau K, Muller S and Waller D: Long-term survival after lung-sparing total pleurectomy for locally advanced (international mesothelioma interest group stage T3-T4) non-sarcomatoid malignant pleural mesothelioma. Eur J Cardiothorac Surg 41: 1031-1036, 2012.

23. Okada M, Mimura T, Ohbayashi C, Sakuma T, Soejima T and Tsubota N: Radical surgery for malignant pleural mesothelioma: Results and prognosis. Interact Cardiovasc Thorac Surg 7: 102-106, 2008.

24. Allen AM, Den R, Wong JS, Zurakowski D, Soto R, Jänne PA, Zellos L, Bueno R, Sugarbaker DJ and Baldini EH: Influence of radiotherapy technique and dose on patterns of failure for mesothelioma patients after extrapleural pneumonectomy. Int J Radiat Oncol Biol Phys 68: 1366-1374, 2007.

25. Stevens CW, Wong PF, Rice D, Jeter M, Forster K and Zhu XR: Treatment planning system evaluation for mesothelioma IMRT. Lung Cancer 49: S75-S81, 2005.

26. Flores RM: Surgical options in malignant pleural mesothelioma: Extrapleural pneumonectomy or pleurectomy/decortication. Semin Thorac Cardiovasc Surg 21: 149-153, 2009.

27. Weder W, Stahel RA, Bernhard J, Bodis S, Vogt P, Ballabeni P, Lardinois D, Betticher D, Schmid R, Stupp R, et al: Multicenter trial of neo-adjuvant chemotherapy followed by extrapleural pneumonectomy in malignant pleural mesothelioma. Ann Oncol 18: 1196-1202, 2007.

28. Batirel HF, Metintas M, Caglar HB, Yildizeli B, Lacin T, Bostanci K, Akgul AG, Evman S and Yuksel M: Trimodality treatment of malignant pleural mesothelioma. J Thorac Oncol 3: 499-504, 2008.

29. Kostron A, Friess M, Inci I, Hillinger S, Schneiter D, Gelpke H, Stahel R, Seifert B, Weder W and Opitz I: Propensity matched comparison of extrapleural pneumonectomy and pleurectomy/decortication for mesothelioma patients. Interact Cardiovasc Thorac Surg 24: 740-746, 2017.

30. Infante M, Morenghi E, Bottoni E, Zucali P, Rahal D, Morlacchi A, Ascolese AM, De Rose F, Navarria P, Crepaldi A, et al: Comorbidity, postoperative morbidity and survival in patients undergoing radical surgery for malignant pleural mesothelioma. Eur J Cardiothorac Surg 50: 1077-1082, 2016.

31. Kostron A, Friess M, Crameri O, Inci I, Schneiter D, Hillinger S, Stahel R, Weder W and Opitz I: Relapse pattern and second-line treatment following multimodality treatment for malignant pleural mesothelioma. Eur J Cardiothorac Surg 49: 1516-1523, 2016.

32. Ploenes T, Osei-Agyemang T, Krohn A, Krohn A, Waller CF, Duncker-Rohr V, Elze M and Passlick B: Changes in lung function after surgery for mesothelioma. Asian Cardiovasc Thorac Ann 21: 48-55, 2013.

33. Bolukbas S, Eberlein M and Schirren J: Prospective study on functional results after lung-sparing radical pleurectomy in the management of malignant pleural mesothelioma. J Thorac Oncol 7: 900-905, 2012 